\title{
A PERSISTENT SUPERIOR VENA CAVA SINISTRA IN THE CAT TRANSMITTING CORONARY BLOOD
}

\author{
S. B. GRANT \\ Washington University \\ ONE FIGURE
}

The anomaly of the vascular system stated in the title was found during a course in comparative anatomy in the Zoology Department of Washington University. At the suggestion of Dr. E. A. Baumgartner, a study of the literature of this form of variation was undertaken, the results of which are here given.

This anomaly was found in a young and apparently normal cat. Upon opening the thoracic cavity, a long slender vein, of uniform diameter, was exposed, which reached from the left innominate vein to the coronary sinus, about $4 \mathrm{~mm}$. distant from its atrial end. This was recognized as a left superior vena cava.

The coronary veins were all of normal size and distribution, and their openings into the coronary sinus were normal. But, the coronary sinus ended blindly about $5 \mathrm{~mm}$. short of the point at which it should have opened into the right atrium. At this end of the sinus it received the vena cordis media. No remnant of a connection could be found upon the blind sinus end or the right atrial wall. Upon tracing the anomalous vena cava upward it was found to open into the left innominate vein at the point where this vein joined with the right to form the normal superior vena cava (fig. 1). In the upper third of its extent the left superior vena cava received the superior intercostal vein, which was composed of two intercostal branches.

Upon examining the interior of the right atrium, no trace of an opening of the coronary sinus was seen. However, the wall 
here was thin. No Thebesian valve was present. The valve of the inferior vena cava, however, was well developed. A large distinct foramen ovale was present.

I have found two references besides those given by McCotter ('16)-LeCat, Beyerlein and Hutton--of anomalies similar to the one under consideration. According to Marshall ('50),

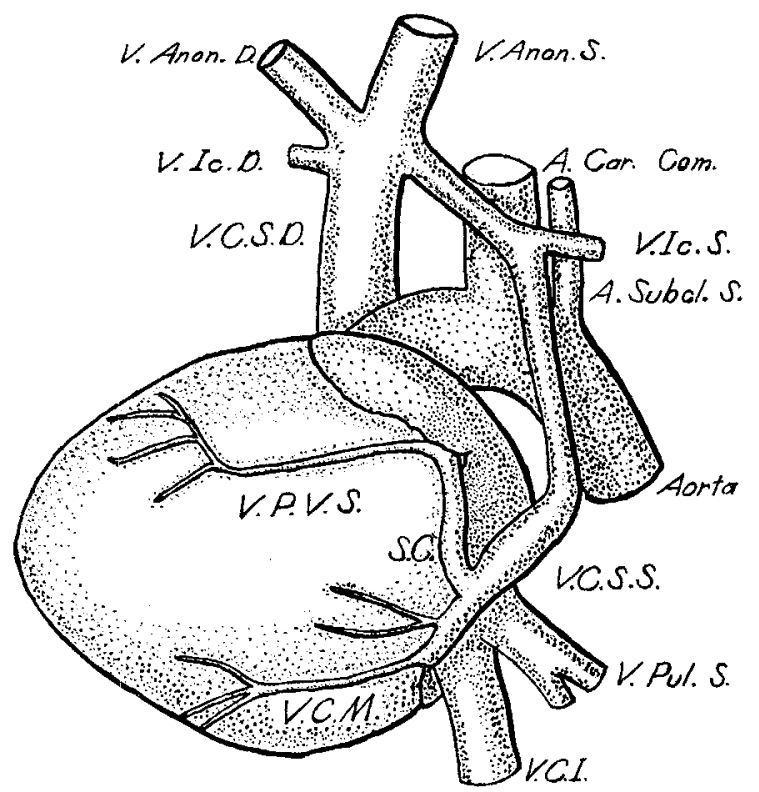

Fig. 1 The heart and vessels viewed from the left and dorsally. It shows the course of the coronary sinus and left superior vena cava. Enlarged one-half.

LeCat observed (1738) a coronary vein which emptied into the left subclavian vein in an eight days old child.

Hutton ('15) found a case in which the coronary sinus ended in a sunken pitted area against the wall of the right atrium. Within the right atrium there was a shallow circular depression corresponding to the coronary opening. There was no Thebesian valve, but a considerable remnant of the left venous valve. Hutton suggested two explanations of the closure of the coronary sinus. The partition between the sinus and atrium was either; first, a composite structure, the result of fusion between 
the coronary segments of the right and left venous valves; or, second, the result of an unusually voluminous Thebesian valve, which had eventually fused with the margins of the ostium of the sinus.

Beyerlein ('14) described a case in a fifteen months old child in which the coronary sinus extended to the wall of the right atrium. Upon observing the interior of the right atrium, all the openings appeared normal, but, upon probing the coronary sinus it was found to be closed. The Thebesian valve, not being mentioned, was evidently normal. Beyerlein offered two possible explanations of his case; viz.: inflammation of the endocardium and atresia, although he saw no evidence of disease; or, a mechanical influence due to suction after the formation of the left innominate, plus pressure in the atrium from the right superior and inferior venae cavae.

Gruber ('85), described, in a fifty years old man, a coronary sinus without any atrial opening. In the right atrium in the place of the usual coronary aperture, there was a small groove leading into a blind pouch $6 \mathrm{~mm}$. deep. Gruber tentatively called the free membranous margin of the groove the Thebesian valve. Anton Siding ('96) also observed a case in an adult male in which the coronary sinus ended blindly $15 \mathrm{~mm}$. short of the site of its opening into the right atrium. Within the right atrium there was a narrow aperture, guarded by a feebly developed Thebesian valve, opening into a blind sac $10 \mathrm{~mm}$. long In all of these cases the coronary sinus drained through a persisting left superior vena cava.

The fact that the left superior vena cava, of the present case, opened into the left innominate so close to the right superior vena cava, instead of some distance from it, is easily explained when one reflects that in the cat, with its narrow thorax, the transverse branch connecting the two superior venae cavae becomes shorter and larger as the embryo increases in size until the left superior vena cava may appear to open into the right at an acute angle.

The closure of the normal ostium of the coronary sinus probably took place after the transverse branch between the two 
superior venae cavae had been formed. As Hutton ('15) suggests, this closure may have been due to an usually large Thebesian valve, which may have closed it too effectively when pressure was exerted upon it from the inside by the flow of blood into the atrium. The left superior vena cava being still open, the coronary blood would find an easy path to the right atrium through it, the left innominate, and the right superior vena cava. If this supposedly large Thebesian valve fused with the wall and permanently closed the normal opening of the coronary sinus, the portion of the latter, or left duct of Cuvier, between the wall of the right atrium and the proximal end of the coronary sinus may have degenerated. It has been suggested by Beyerlein ('14), that the suction in the left superior vena cava, caused by the rush of blood in the left innominate vein would aid in closing the normal sinus opening. That the Thebesian valve, which is formed from the caudal portion of the right valve of the sinus venosus, may have been abnormal and possibly concerned with the closure of the coronary opening, is indicated by its absence and also by the presence of a patent foramen ovale. If the left venous valve were abnormally small, it may have resulted in the failure of the foramen ovale to close, and in such a case, the right venous valve' would be likely to be unusually large, and, consequently, the Thebesian valve as well.

Gruber's and Siding's cases are similar to the present, in that the coronary sinus ended before reaching the wall of the right atrium; but differ in that in my case there is no cul-de-sac or opening in the atrium at the site of the normal ostium of the sinus. Hutton's and Beyerlein's cases differ from the writer's and the other two, in that the coronary sinus in these cases extends to the wall of the right atrium, where it is closed.

Hutton's second suggestion as to causes of the anomaly seems to suit the case here described, but the fusion of the Thebesian valve to the atrial wall in my case must have taken place so early in development that no traces of it are left. Coupled with this may have been the mechanical causes suggested by Beyerlein. 


\section{LITERATURE CITED}

Bhyerlein, K. 1914 Die persistierende Vena cava superiore sin istra als Abflussrohr für das Coronarvenenblut. Frankfurter Zeitsch. f. Path., Bd. 15.

Gruber, W. 1885 Anatomische Notizen. Arch. f. path. Anat., Bd. 19.

Hutron, W. K. 1915 An anomalous coronary sinus. Jour. Anat. Phys., vol. 49.

Keibel and Mall 1912 Manual of Human Embryology. Lippincott, Philadelphia.

LECAT, 1738 Histoire de l'academie des Sciendes. Paris, 1840. (Quoted from Marshall.)

Marshald, J. 1850 On the development of the great anterior veins, etc. Phil. Trans. Royal Soc., London, vol. 141.

McCotter, R. E. 1916 Three cases of the persistence of the left superior vena cava. Anat. Rec., vol. 10.

Siding, A. 1896 Ueber den Abfluss des Sinus coronarius cordis gegen den rechten Vorhof. Anat. Anz., Bd. 12. 